\title{
Combined deficiencies of Src, Fyn, and Yes tyrosine kinases in mutant mice
}

\author{
Paul L. Stein, ${ }^{1}$ Hannes Vogel, ${ }^{2}$ and Philippe Soriano ${ }^{1,3}$ \\ ${ }^{1}$ Program in Molecular Medicine, Fred Hutchinson Cancer Research Center, Seattle, Washington 98104 USA; ${ }^{2}$ Department \\ of Pathology, Baylor College of Medicine, Texas Childrens Hospital, Houston, Texas 77030 USA
}

Three members of the Src family of tyrosine kinases, src, fyn, and yes, are broadly expressed throughout mouse development. Mutations in the c-src and fyn genes were shown previously to lead to restricted nonoverlapping phenotypes only in a subset of cells in which these kinases are expressed. In this work we show that a mutation in the yes gene does not lead to an overt phenotype. Except for brain, the level or distribution of related kinases is not altered in major tissues. To gain further insight into the possibility that these kinases compensate for each other, animals deficient in multiple src-kinases were generated. Whereas most of the $s r c / f y n$ or $s r c / y e s$ double mutants die perinatally, a substantial proportion of fyn/yes double mutants are viable but undergo degenerative renal changes leading to diffuse segmental glomerulosclerosis. Taken together, these data are consistent with the hypothesis that, at least in some cells, these kinases are able to compensate for the loss of the other related kinases.

[Key Words: Tyrosine kinase; mouse genetics; Src; Fyn; Yes]

Received June 6, 1994; revised version accepted July 7, 1994.

The Src family tyrosine kinases, first identified as transforming genes present in some retroviruses (Stehelin et al. 1976), have been implicated in a variety of cellular processes. To date, nine different family members have been isolated of which three, Src, Fyn, and Yes, are broadly expressed in a variety of cell types, whereas the remainder are restricted primarily to hematopoietic cells. Other than the oncogenic potential, little is known about the physiological roles governed by these kinases. A number of biochemical studies have suggested that the src-like gene products are linked to signaling systems within the cell. These kinases can physically associate with a diverse number of cell-surface molecules and increase in catalytic activity following cross-linking of the surface molecule (Ralston and Bishop 1985; Tsygankov et al. 1992); however, the evidence that any individual kinase is crucial for signaling is scant. This is complicated by the observation that in a number of cases, multiple Src family members bind to the same receptor, raising the possibility that various members may functionally substitute for each other if one of the kinases becomes inactivated (Kypta et al. 1990; Burkhardt et al. 1991; Courtneidge et al. 1993). For example, the SH2 domains from Src, Fyn, and Yes probably mediate the binding of these kinases to identical residues on the platelet-derived growth factor- $\beta$ (PDGF- $\beta$ ) receptor in fibroblasts and to the cognate amino acids in the CSF-1 receptor (Twamley et al. 1992; Courtneidge et al. 1993). These interactions appear to be functionally important

${ }^{3}$ Corresponding author. as well (Twamley-Stein et al. 1993). Thus, the action of Src-related kinases may appear redundant within this context because each member associates with the same signaling apparatus (e.g., PDGF receptor), yet in other tissues a Src family member may interact with a distinctive effector molecule, a process that cannot be compensated for by the other family members.

Recent work utilizing a genetic approach has generally supported but not proven the concept that compensatory interactions occur between these kinases. Animals deficient in the more widespread $s r c$-like kinases have restricted phenotypes that do not necessarily correlate with levels of expression. Similarly, mutations in kinases expressed in a limited number of cell types also have a variety of effects. Disruption of $1 c k$ blocks T-cell development (Molina et al. 1992), whereas mutations in $h c k$ and $f g r$, two Src family kinases expressed predominantly in macrophages, cause little or no phenotype. However macrophages lacking both hck and fgr fail to clear Listeria infections (Lowell et al. 1994). Despite the fact that Src is relatively abundant in brain, platelets, and osteoclasts (Cotton and Brugge 1983; Golden et al. 1986; Horne et al. 1992), only osteoclasts appear dysfunctional. This leads to the bone-remodeling disease, osteopetrosis (Soriano et al. 1991; Lowe et al. 1993). Disruption of the fyn gene perturbs T-cell receptor-mediated signaling in thymocytes but has minimal effects on mature T cells (Appleby et al. 1992; Stein et al. 1992). This mutation also affects some aspects of hippocampal organization and function (Grant et al. 1992). However, other brain regions and tissues expressing fyn do not appear to 
display a phenotype. Coupling the phenotypes observed in these mice with the fact that Src, Fyn, and Yes are often coexpressed in the same cell suggests that the absence of more severe phenotypes may be attributable to functional compensation between kinases.

Because pp62-yes is often coexpressed with c-Src and Fyn, we have generated c-Yes-deficient mice by disrupting the c-yes gene in embryonic stem (ES) cells. These mice have no overt phenotype, nor have we been able to detect any histopathological abnormalities associated with the mutation. By crossing mice lacking c-src, fyn, or c-yes, the phenotypes resulting from the combined deficiencies can be assessed. In addition biochemical analysis of the mutants may reveal changes in expression of the different kinases. We now show that although the overall levels of Src family kinases do not appear altered in tissues examined, c-Src shows a selective increase in solubility from $\mathrm{fyn}^{-}$brains. Crossing of Src family mutants with each other leads to more severe phenotypes than observed in single mutants. The vast majority of mice lacking $s r c$ and yes or $s r c$ and fyn die shortly after birth, whereas fyn/yes double mutants develop a renal disease characterized as diffuse segmental glomerulosclerosis. The increased severity of the phenotypes indicates that although these kinases are generally dispensable for embryonic development, they are apparently critical for general homeostasis following birth.

\section{Results}

\section{Derivation of yes mutant mice}

Two types of constructs were used to disrupt the c-yes gene. The first vector utilized a neo expression cassette inserted into an exon to cause the disruption, and a second vector was designed to act as a "gene trap" because the yes gene is expressed in ES cells. In both cases, the targeting vectors contained $10 \mathrm{~kb}$ of c-yes homologous sequences. Either a neo expression cassette (PolllsneobpA; Soriano et al. 1991) or an in-frame promotorless $\beta$-gal-neo fusion ( $\beta$-geo; Friedrich and Soriano 1991) was inserted at a XhoI site in exon 7 (Klages et al. 1993) to serve as the mutagen, $1.3 \mathrm{~kb}$ from the $3^{\prime}$ end of the construct (Fig. 1A). Following electroporation of the neotargeting construct into $\mathrm{AB} 1$ cells (McMahon and Bradley 1990), 25/44 pools representing a total of 1084 ES cell clones were scored positive by a PCR assay, indicating a minimum targeting frequency of 1 in 43. Further screening of six pools led to the identification of nine positive clones. As expected with the $\beta$-geo construct, fewer colonies were observed, and 6 of a total of 18 were identified as positives. Southern blot analysis using a flanking c-yes probe confirmed that the constructs had undergone homologous recombination at the locus with no rearrangements (Fig. 1B). Hybridization of the blots with neo or plasmid probes confirmed the presence of a single neo or $\beta$-geo copy at the locus (data not shown).

Three neo clones and one $\beta$-geo clone were used to derive germ-line chimeras, which were then bred to C57BL/6J or $129 \mathrm{~Sv}$ females. The chimeras gave rise to hybrid or inbred mutant mouse lines yes1, yes2, yes3, and yes $\beta$-geo, respectively. Heterozygous yes mice did not display an overt phenotype, and yes $\beta$-geo mice were used to examine the pattern of expression of yes during embryonic development. As shown in Figure 2, the yes

\section{A}

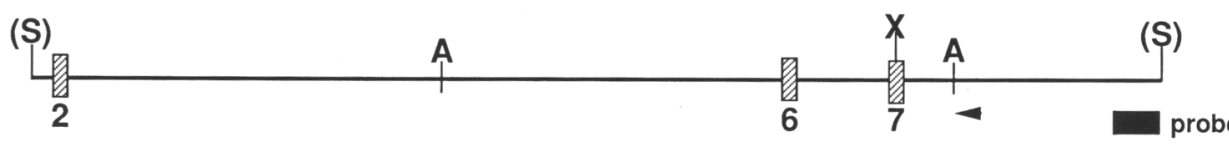

$1 \mathrm{~kb}$
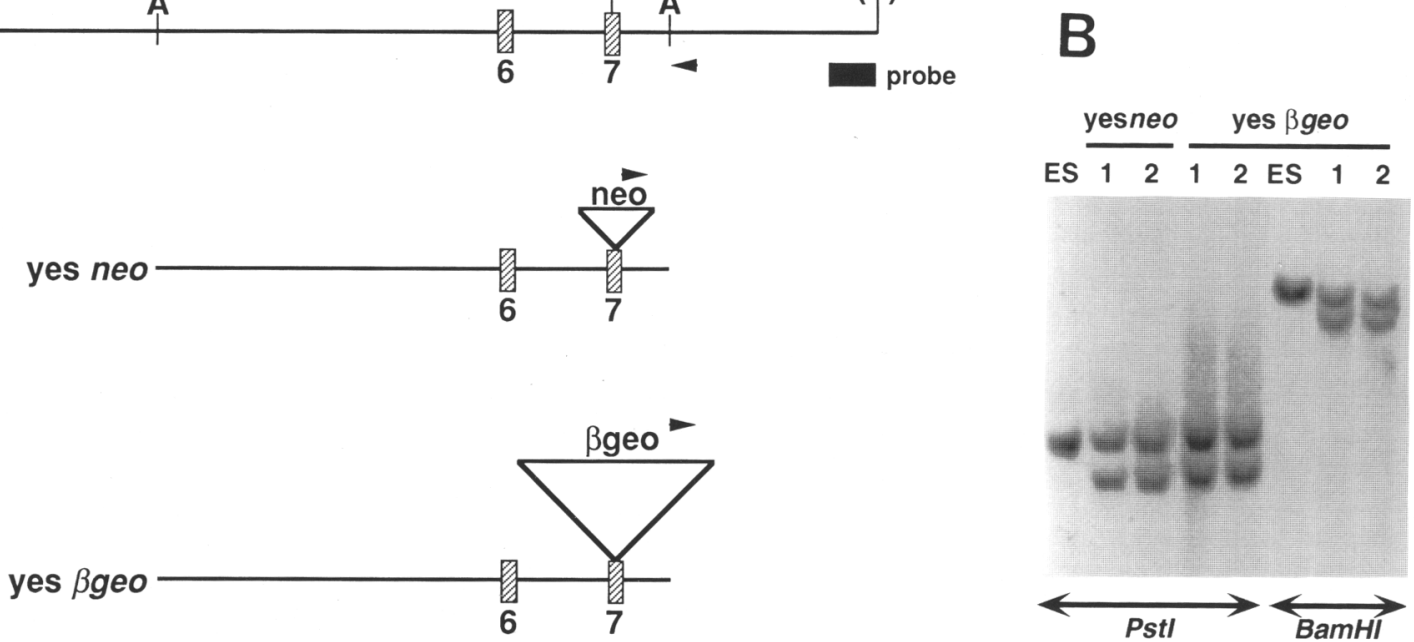

Figure 1. Disruption of the c-yes locus. (A) Restriction map of the c-yes gene and targeting vector. A 10-kb ApaI fragment of the c-yes gene was linearized at the XhoI site in exon 7 and either the neo expression cassette or $\beta$-geo was inserted. Restriction endonuclease sites are abbreviated as follows: (X) XhoI; (A) ApaI. The genomic fragment is flanked by Sall sites derived from the cloning vector and is denoted by S. Arrows indicate PCR primers. $(B)$ Genomic analysis of PCR-positive ES colonies. Genomic DNA from different colonies was isolated and digested with PstI or BamHI and analyzed by Southern blot hybridization using a probe $3^{\prime}$ of the predicted insertion site. PstI cuts within the neo gene and BamHI cleaves at the junction between $\beta$-galactosidase and neo components of $\beta$-geo. 
gene is broadly expressed at mid-gestation [embryonic day (E13)], as judged by the staining pattern of $\beta$-galactosidase.

Heterozygous mice were bred and gave rise to homozygous progeny according to Mendelian expectations. Although c-Yes can be found in numerous tissues, it is highly expressed in lung, skin, sperm, and cerebellum (Zhao et al. 1990). However, no sign of skin lesions or blistering was apparent in the mutant, nor was there evidence of locomotor dysfunction. The mutants were viable, fertile, and displayed no overt phenotype. Histological analysis of the homozygous mutants failed to reveal any abnormalities in $>20$ tissues examined (data not shown; see Materials and methods). To test the absence of Yes in the mutants, protein extracts from wildtype, heterozygotes, and homozygous mutants were made from brain. No Yes-specific polypeptide could be observed in Western blots of mutant extracts, using an antibody directed against the amino-terminal "unique" domain of the protein (Fig. 3), nor was c-Yes immunoreactivity detected in extracts from spleen, kidney, lung, and thymus (data not shown). Likewise, antibodies failed to immunoprecipitate any kinase activity from brain extracts (Fig. 3). Thus, it appears that this mutation, introduced at the beginning of the kinase domain, does lead to a null mutation in the gene.

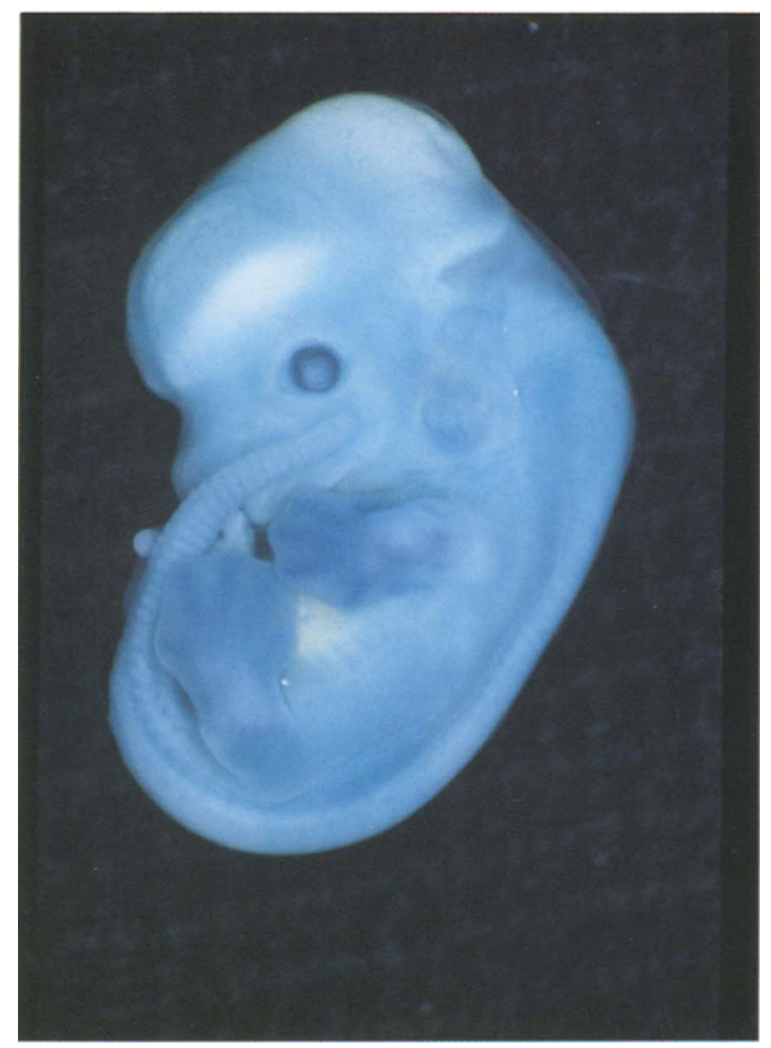

Figure 2. Pattern of $\beta$-galactosidase activity in yes $\beta$-geo embryos. E13 embryos were fixed and stained with X-gal to reveal the spatial pattern of $\beta$-galactosidase expression driven from the c-yes locus.

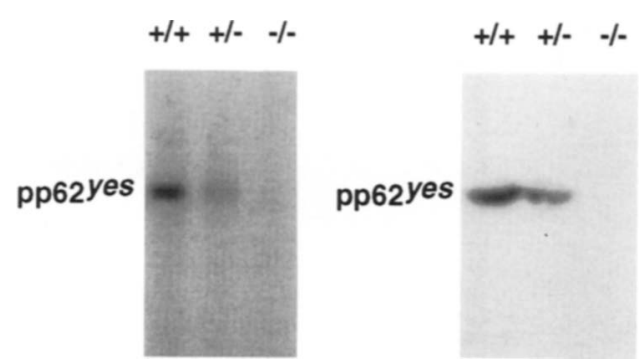

Figure 3. Protein assay for the c-Yes gene product. (Left) In vitro kinase assay. Brain extracts for wild-type, heterozygous, or mutant animals were immunoprecipitated with antisera recognizing the human c-Yes protein and incubated with $\left[\gamma^{32} \mathrm{P}\right] \mathrm{ATP}$. Products were identified by autoradiography of a $7.5 \%$ polyacrylamide gel. (Right) Immunoblot of brain extracts. Protein $(150 \mu \mathrm{g})$ was separated on a $8 \%$ polyacrylamide gel, electroblotted onto nitrocellulose, and incubated with the anti-Yes $\mathrm{mAb}$ $3 \mathrm{H} 9$. Genotypes were denoted as wild type $(+1+1$; heterozygous $(+/-)$; and mutant $(-1-)$.

Because Yes is also highly expressed in T cells, and the related Fyn kinase has been shown to be involved in signaling from the T-cell receptor, thymocytes and mature splenic $T$ cells from mutant mice were compared with wild type in terms of calcium mobilization and proliferation in response to engagement from the T-cell receptor. No difference was observed (data not shown).

\section{$c$-Src has altered solubility in the mutants}

One explanation for the restricted phenotypes in mutants lacking Src-like kinases is that other members of the gene family may become reregulated and serve a surrogate role. Protein levels of the different Src-related kinases were assessed by immunoblots after homogenizing tissues from wild-type, fyn, yes, src, and fyn/yes mutants. Tissues were extracted in either the mild nonionic detergent digitonin to release the most freely soluble proteins or boiled in SDS sample buffer to solubilize all protein components. The following tissues were examined: brain, thymus, lung, spleen, kidney, liver, and fyn / yes-deficient fibroblasts. No differences in the levels of Src kinases were observed in RIPA or SDS extracts from any of the tissues, nor were changes observed in digitonin extracts from any of the tissues except brain. Contrary to a report published previously demonstrating that Lck ectopically expressed in fibroblasts associates with the cytoskeleton (Louie et al. 1988), Lck in thymocytes is readily extracted by digitonin (data not shown). In addition, kinase activity of Src, Fyn, or Yes in RIPA extracts of the different tissues was not altered by the mutant backgrounds. In the tissues examined, up-regulation of various Src family kinases does not appear to occur.

In contrast, digitonin lysates from fyn-deficient brains contained twice as much c-Src relative to wild-type samples (Fig. 4). These results demonstrate an inherent difference in the ability of this kinase to be extracted and indicate that in $\mathrm{fyn}^{-}$brains $\mathrm{c}-\mathrm{Src}$ is in a more soluble 


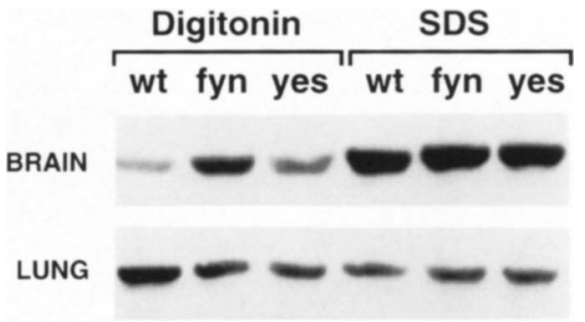

Figure 4. Comparison of Src levels in the mutants. Wild-type (wt) or mutant tissue was extracted in either digitonin or sample buffer, and analyzed by immunoblot. A total of six wild-type and six mutant brains were examined. There is a consistent increase in the amount of c-Src recovered from digitonin extracts of $f_{y n}{ }^{-}$brains ( $\sim$ twofold) relative to wild-type or c-yes mutant brains. Although there appears to be more $\mathrm{c}$-Src in the wild-type lung sample, no consistent differences were noted in other experiments.

fraction. The ease of extraction by digitonin is consistent with a change in the subcellular distribution of $\mathrm{c}$-Src in the $\mathrm{yyn}^{-}$brain. The shift in kinase localization may be attributable to less Src associated with the brain cytoskeletal elements. Similar observations have been noted in other systems. In resting platelets c-Src is more cytosolic; following thrombin stimulation $s r c$ is activated and translocates to the cytoskeleton /Clark and Brugge 1993). An in-depth analysis of the changes in brains from the mutants will be presented elsewhere (S. Grant and E. Kandel, pers. comm.).

\section{Crosses between kinase mutants}

One possibility to explain the lack of a phenotype in the yes mutant is that other Src-like kinases functionally substitute for the loss of this gene product. One way to address this is to cross c-yes-deficient mice with the src and fyn mutants characterized previously. Matings were also set up between mice harboring mutations in fyn and src, as well as between all three kinase mutants. All mice used in the study were hybrid C57BL6J/129Sv mice, because of the poor fecundity of inbred $129 \mathrm{~Sv}$ mice. Thus, some of the variability in penetrance that we have observed might be attributable to differences in the genetic background.

Animals were genotyped between 10 days postpartum and weaning; the results are shown in Table 1. Crosses between parents heterozygous for two kinases (fyn and src, yes and src, and fyn and yes) should be expected to produce double homozygous mutants at a frequency of 1 in 16 . We recovered only on the order of $10 \%$ of the expected number for breedings involving src, but $\sim 35 \%$ for crosses involving fyn and yes. To increase the frequency of double mutants, we took advantage of the fact that fyn and yes mutants breed as homozygotes, and mated animals that were mutant for one of these genes and heterozygous for one of the other kinase genes. Utilizing this strategy, one in four animals should be double homozygous mutants. Similar percentages of double mutants were observed from these crosses relative to progeny derived from compound heterozygotes. In practice, this approach was not efficient for analyzing $f y n / s r c$ double mutants, because $f_{y n}{ }^{--} s r c^{+-}$mothers showed de-

Table 1. Breeding data from src family intercrosses

\begin{tabular}{|c|c|c|c|c|c|}
\hline \multirow[b]{2}{*}{ Double mutants } & \multirow[b]{2}{*}{ Parents } & \multirow[b]{2}{*}{ Progeny screened } & \multicolumn{2}{|c|}{ Double mutants } & \multirow[b]{2}{*}{ Percent expected } \\
\hline & & & expected & observed & \\
\hline $\mathrm{fyn} / \mathrm{src}$ & $\begin{array}{l}\text { fyn }^{+-} \text {src }^{+-} \\
\text {fyn }^{+-} \text {src }^{+-} \text {yes }^{+-}\end{array}$ & $\begin{array}{l}619 \\
166\end{array}$ & $\begin{array}{l}32 \\
10\end{array}$ & $\begin{array}{l}5 \\
1^{\mathrm{a}}\end{array}$ & $\begin{array}{l}15 \\
10\end{array}$ \\
\hline Total & & & 42 & 6 & 14 \\
\hline yes/src & $\begin{array}{l}\text { yes }^{+-} \text {src }^{+-} \\
\text {yes }^{--} \text {src }^{+-} \\
\text {fyn }^{+-} \text {src }^{+-} \text {yes }^{+-} \\
\text {fyn }^{+-} \text {src }^{+-} \text {yes }^{--}\end{array}$ & $\begin{array}{l}200 \\
444 \\
166 \\
146\end{array}$ & $\begin{array}{r}12 \\
111 \\
10 \\
36\end{array}$ & $\begin{array}{l}2 \\
9 \\
1^{b} \\
4^{b}\end{array}$ & $\begin{array}{r}16 \\
8 \\
10 \\
11\end{array}$ \\
\hline Total & & & 169 & 16 & 9 \\
\hline fyn/yes & $\begin{array}{l}\text { fyn }^{+-} \text {yes }^{+-} \\
\text {fyn }^{--} \text {yes }^{+-} \\
\text {fyn }^{+-} \text {yes }^{--} \\
\text {fyn }^{+-} \text {src }^{+-} \text {yes }^{+-} \\
\text {fyn }^{+-} \text {src }^{+-} \text {yes }^{--}\end{array}$ & $\begin{array}{l}268 \\
263 \\
316 \\
166 \\
146\end{array}$ & $\begin{array}{l}17 \\
66 \\
79 \\
10 \\
36\end{array}$ & $\begin{array}{c}6 \\
15 \\
30 \\
2^{\mathrm{c}} \\
20^{\mathrm{c}}\end{array}$ & $\begin{array}{l}35 \\
22 \\
38 \\
20 \\
55\end{array}$ \\
\hline Total & & & 208 & 73 & 35 \\
\hline
\end{tabular}

Genotypes were determined by Southern blots of DNA obtained from tail biopsies on 10-day-old animals.

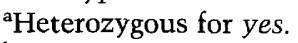

${ }^{b}$ Of these mice, 4 were wild type and 1 was heterozygous for $f y n$.

'Of these mice, 18 were wild type and 4 were heterozygous for src. 
creased fertility and difficulty in nursing newborn pups in occasional cases when they became pregnant. These characteristics were never observed in $f_{y n}{ }^{--}$or $\mathrm{src}^{+-}$ mice, and combining these genotypes represents one instance of a gene dosage effect, or haploinsufficiency, on the overall physiology of the animal.

The low frequency of double mutant progeny recovered in each cross suggests a significant amount of embryonic lethality. To test this hypothesis, embryos were delivered by cesarean section at E18, $\sim 1$ day prior to birth, and examined for survival, weight, and by histology. A normal Mendelian number of mutants were present (Table 2). For both fyn/yes and fyn/src mutants, weights were similar to wild-type littermates. In contrast, src/yes double mutants were systematically $\sim 25 \%$ smaller than their littermates in crosses involving yes $^{--}$src $^{+-}$(Fig. 5) and only started to breathe regularly following $1 \mathrm{hr}$ of gentle prodding, whereas their littermates started breathing much more quickly. The small size of these mice was not accompanied by any marked diminution in the mass of the placenta. Histological analysis of these mutants failed to reveal any abnormality. However, a significant number of progeny from these crosses were shown to be dead shortly after birth (not shown). Southern blot analysis revealed that the majority of these were double mutants. Although the expression of multiple Src family kinases is not essential during embryonic development, double mutant pups may not be able to compete for nursing against their wildtype or heterozygous littermates and thus are selected against shortly after birth.

The surviving $f y n / s r c$ or yes/src mutants were very small, compared with their wild-type or $\mathrm{src}^{-}$littermates. fyn/src double mutants, in particular, weighed on average only 3-4 grams at 3 weeks of age and did not survive past this age. Littermates weighed $\sim 8$ grams. In contrast, some yes/src double mutants were able to survive longer, and one mouse has survived 1 year, on a soft food diet. Histopathological analysis revealed no abnormalities other than the osteopetrosis caused by the src mutation (data not shown). It is possible therefore, that these double mutants die because of general growth retardation.

\section{Phenotype of fyn/yes double mutants}

Approximately one-third of fyn/yes mutants were viable and initially remained healthy (Table 1). The absence of

Table 2. Double mutants recovered at E18

\begin{tabular}{lccc}
\hline & & \multicolumn{2}{c}{ Double mutants } \\
\cline { 3 - 4 } Parents & Embryos screened & expected & observed \\
\hline fyn $^{--}$src $^{+-}$ & 60 & 15 & 15 \\
yes $^{--}$src $^{+-}$ & 72 & 18 & 15 \\
fyn $^{--}$yes $^{+-}$ & 30 & 7 & 11 \\
fyn $^{+-}$yes & 26 & 6 & 4 \\
\hline
\end{tabular}

Genotypes were determined by Southern blots from yolk sac DNA from E18 embryos.

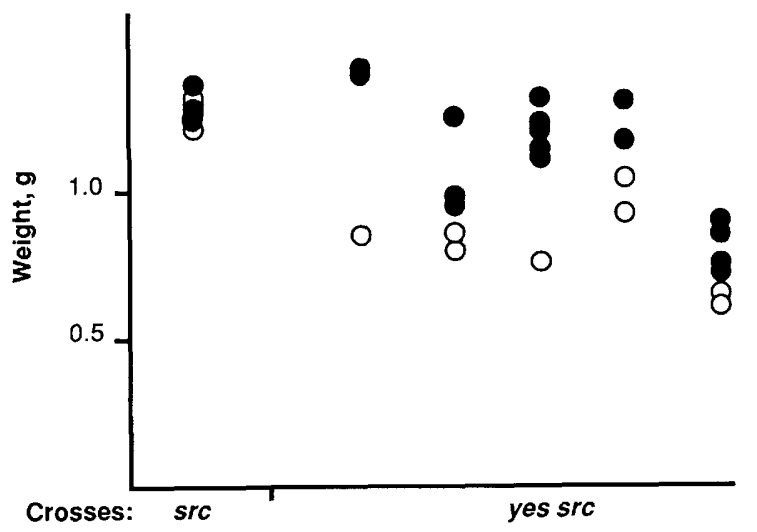

Figure 5. Weights of embryonic src/yes double mutants. E18 embryos were removed by cesarian section, and placenta and embryo were weighed. No major differences were observed in placenta weight. Each symbol represents a single embryo. (O) src $^{-}$homozygotes; (O) littermates that are either wild type or heterozygous at the $s r c$ locus. Each column represents a single litter of pups. All src/yes embryos were derived from parents that were yes ${ }^{-} \mathrm{src}^{+-}$. The weight differences between $\mathrm{src} / \mathrm{yes}$ mutants and littermates was statistically significant $(\mathrm{P}<0.05)$. A litter of src embryos is included for comparison.

normal numbers of double mutants at weaning again suggests loss at earlier stages. As shown in Table 2, there was no evidence of embryonic lethality. As these animals were generally smaller than their littermates at weaning, it is possible that some animals are selected against because of general growth retardation. At about 3-5 months of age, however, many homozygotes began to lose weight and develop ruffled fur. Closer examination revealed a number of anomalies, in addition to the abnormal undulations of the $\mathrm{CA} 3$ region and the dentate gyrus observed previously in single fyn mutants (Grant et al. 1992). Animals possessed enlarged spleens because of prominent myeloid hyperplasia and expansion of the white pulp, and in some cases, a significant degree of extramedullary hematopoiesis.

The most significant defect in the double mutant fyn/ yes mice, however, was associated with renal pathology. Grossly the kidneys were pale, shrunken, and exhibited pitting of the surface. All double mutants examined displayed a progressive glomerulopathy that was evident as early as 5 weeks of age. This was accompanied by high levels of proteinurea $(>100 \mathrm{mg} / \mathrm{dl})$ and, in most cases, the presence of leukocytes and erythrocytes in the urine. The earliest glomerular lesion was a diffuse mesangial hypercellularity in focal glomeruli. Analysis of more advanced lesions revealed segmental glomerulosclerosis, highlighted by positive periodic acid Schiff's (PAS) staining of the mesangium and the sclerotic segments of the affected glomeruli (Fig. 6A). Sclerotic segments of glomeruli were also stained positively by the Gomori trichrome stain. The renal interstitium in all double mutants displayed tubal ectasia and a variable chronic inflammatory cell infiltrate. Fluorescence immunohistochemistry revealed deposition of $\operatorname{IgG}$ in the mesangium 
Figure 6. Pathological abnormalities in fyn/yes kidneys. (A) Renal glomerulus of fyn/yes-deficient mouse demonstrating mesangial hypercellularity (white arrow) and segmental sclerosis with foam cells (white arrowhead). PAS staining. Magnification, $264 \times$. (B) Accumulation of immunoglobulin deposits in glomerulus. Frozen section of less advanced lesion stained for presence of IgG and showing abnormal accumulation of immunoglobulin in mesangial distribution. Magnification, $132 \times(C)$ Electron micrograph of expanded mesangial matrix (m) from abnormal glomerulus and paramesangial deposits (black arrow). Magnification, $7590 \times$; original magnification, $5000 \times$.
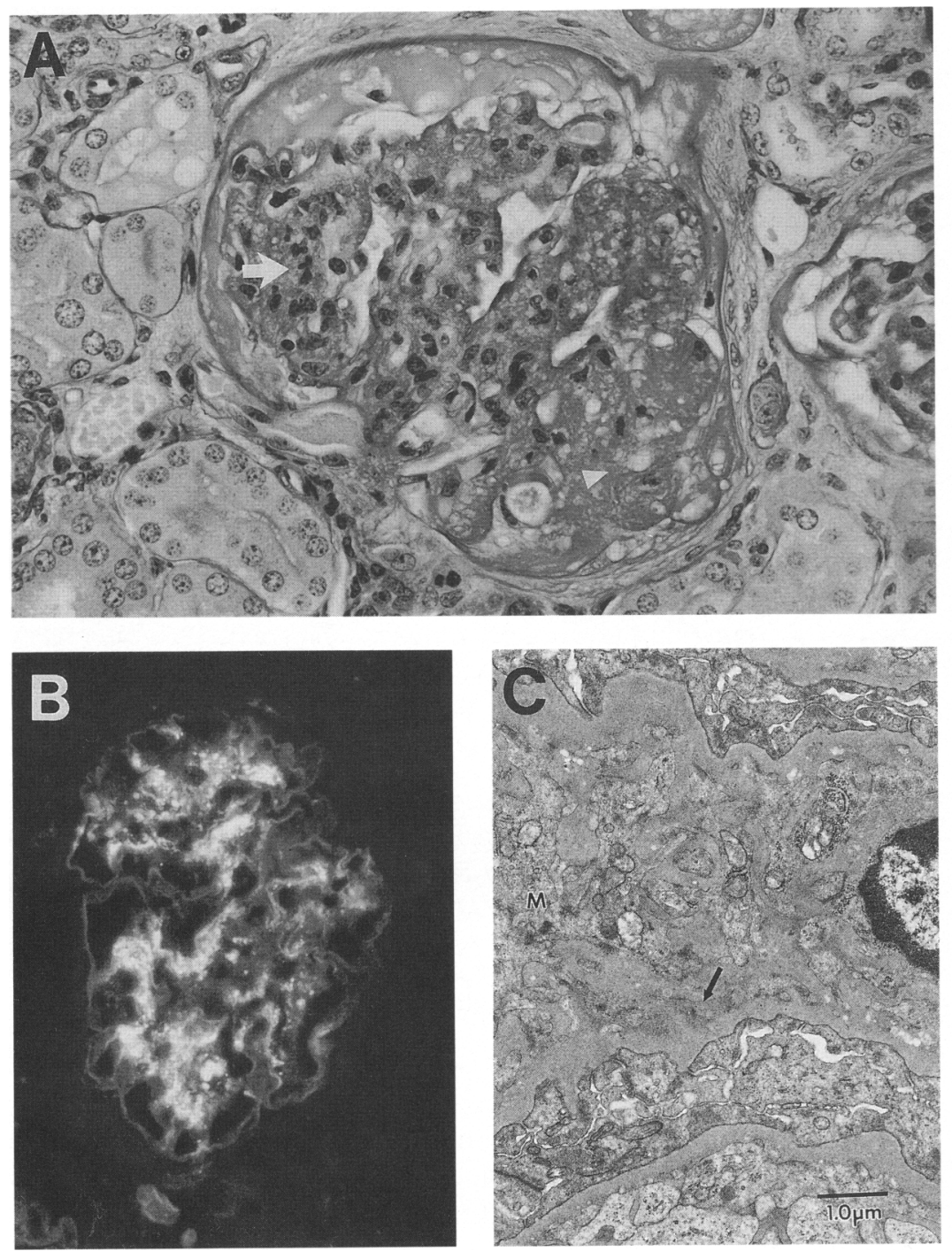

(Fig. 6B). In addition, there was a mesangial accumulation of $\operatorname{IgM}$ and $\operatorname{IgA}$, as well as a global glomerular deposition of complement C3 (data not shown). Electron microscopy of mutant glomeruli indicated that the mesangial matrix was expanded and accompanied by paramesangial deposits (Fig. 6C).

Because many of the features observed in double mutant mice are similar to those characterized by an autoimmune disease, serum was screened for the presence of anti-nuclear antigen or anti-DNA antibodies. These studies failed to reveal the presence of such activity (data not shown). In addition, frozen sections from various tissues were stained with sera for the presence of autoreactive antigens, and none were found. Because a link between Fyn activity and proper responses following T-cell receptor activation have been identified previously (Cooke et al. 1991; Appleby et al. 1992; Stein et al. 1992), further perturbations of this signaling system may occur in fyn/yes double mutants. Thymocytes and splenic $\mathrm{T}$ cells were characterized for their ability to re- spond following T-cell receptor activation. No differences were noted between $f_{y n}{ }^{-}$and $f y n / y e s$ mutants in their capacity to flux calcium or proliferate following cross-linking of the T-cell receptor. In addition, the serum immunoglobulin profiles were identical to wildtype animals. In an attempt to establish more firmly an association between the phenotype and hematopoietic system, fyn ${ }^{-} /$yes $^{-}$bone marrow or spleen cells were injected into lethally irradiated wild-type mice with the expectation that the recipients would manifest the pathologies associated with the double mutant. After 6 months no kidney abnormalities have been noted; however, irradiation is known to suppress autoimmune phenomena.

\section{Discussion}

Of the nine $s r c$ family members identified, only three (src, yes, and $f g r$ ) were originally isolated as viral transforming genes. For each of the three kinases, oncogenic- 
ity correlates with alterations in the carboxy-terminal sequences, leading to unregulated kinase activity. Normally this is controlled by phosphorylation of a carboxyterminal tyrosine residue by at least two kinases, Csk (Okada et al. 1991) or Ctk (Klages et al. 1994). Loss of Csk results in activation of the Src kinases with subsequent embryonic lethality (Imamoto and Soriano 1993; Nada et al. 1993). On the other hand, loss-of-function mutations created by targeted disruption of these genes in mice produces either a restricted phenotype, as observed in $s r c$ (Soriano et al. 1991), or no overt dysfunctional consequences in the case of fgr (Lowell et al. 1994). In this work, we show that a mutation in the third member, yes, also has no discernible effect. This result is unexpected because yes is widely expressed and highly enriched in the cerebellum, lung, and platelets (Zhao et al. 1990).

The apparent lack of phenotype in yes mutant mice might be attributable to compensatory interactions between genes. These may encode other src family members, or tyrosine kinase-specific substrates, as has been observed in Drosophila (Gertler et al. 1993). The compensatory action can occur at several levels. First, the presence of other family members within the cell may effectively substitute for c-yes and succeed in overriding a block in pp62-yes -mediated signaling. Second, there may be a selective increase in expression of various family members (e.g., Rudnicki et al. 1993); and third, the catalytic activity of different members may change. It is notable that $h \mathrm{ck}^{-}$macrophages have increased specific activity of Lyn (Lowell et al. 1994), which may explain the dearth of a phenotype in these cells.

Except brain, there does not appear to be changes in total levels of Src kinases or subcellular distribution within the tissues analyzed. The implication is that this mode of regulation clearly is not a general mechanism even in phenotypically affected tissues such as thymus and spleen. In fyn mutant brains, however, Src was extracted more easily by digitonin. The increased level of soluble Src may form part of a compensatory pathway that results in increased accessibility to various substrates normally utilized by Fyn.

Alternatively, the change in localization of Src from its normal subcellular compartments may be attributable to a less "activated" state of the mutant tissue. In several instances, Src has been documented to undergo subcellular translocation following activation. After thrombin treatment of platelets, activated Src molecules migrate to the cytoskeleton (Clark and Brugge 1993). Likewise PDGF stimulation of fibroblasts releases Src from the membrane (Walker et al. 1993), and oncogenic forms of Src are associated primarily with the cytoskeleton in fibroblasts (Hamaguchi and Hanafusa 1987). Although the precise biochemical pathway is not understood, it is plausible that the phenotypic defect noted in fyn ${ }^{-}$brains is manifest by a failure of receptor activation that normally induces Src to migrate to the cytoskeleton or more detergent-resistant fractions.

The lack of a demonstrable phenotype associated with the c-yes mutation may be attributable to compensation via homeostatic mechanisms as well. Src-like kinases probably modulate signaling responses, especially under suboptimal stimulus conditions. Several studies analyzing the function of Fyn support this view. Although the T-cell receptor complex is functional in $f_{y n}{ }^{-}$lymphocytes, $\mathrm{Ca}^{2+}$ mobilization triggered by receptor activation is attenuated and further exacerbated under suboptimal conditions (Appleby et al. 1992; Stein et al. 1992). Mutant hippocampi show impaired long-term potentiation (LTP), but a strong stimulus still can elicit a LTP response (Grant et al. 1992). The process of myelination activates Fyn kinase activity, and mice harboring one type of fyn mutation exhibit inefficient myelination (Umemori et al. 1994). Thus, a primary signaling pathway may remain functional in the absence of these kinases, but the signal transduction events occur less efficiently. This would effectively mask the requirement for c-yes or any of the family members.

The hypothesis that Src family kinases may be able to compensate for each other is consistent with a number of experimental observations. Mice lacking hck and $f g r$ are sensitive to Listeria infections presumably because of defective macrophage function, whereas the single mutants clear the bacteria effectively (Lowell et al. 1994). The data presented in this paper show that animals deficient in the broadly expressed kinases $s r c$ and yes, or src and fyn, rarely survive past birth. Further analysis will be required to understand the nature of the defect in double mutant neonates. However, analysis of the fyn/yes-deficient mice revealed that approximately onethird of the animals survive to adulthood, but most develop a renal disease attributable to glomerulosclerosis. This phenotype is particularly striking because of the expression pattern for fyn and c-yes. Although the c-yes gene product has been identified in the renal tubules, immunocytochemistry has demonstrated very little pp62 ${ }^{\text {c-yes }}$ within the glomerulus itself (Zhao et al. 1990). More importantly the kidney does not express Fyn as judged by Northern analysis and immunoblots (Cooke and Perlmutter 1989; P.L. Stein, unpubl.). These results indicate that the glomerular lesions are a secondary consequence of the mutations.

The sclerotic lesions in the fyn/yes kidneys are reminiscent of the pathologies associated with autoimmune disease, suggesting that the primary defect may lie in $\mathrm{T}$ cells. Both fyn and yes are coexpressed in T cells, and fyn $^{-} \mathrm{T}$ cells exhibit defective T-cell receptor signaling (Appleby et al. 1992; Stein et al. 1992). Whereas double mutant $\mathrm{T}$ cells do not demonstrate more severe defects by a number of in vitro assays, in vivo growth and activation may lead to inappropriate responses. Humans suffering from glomerulosclerosis sometimes have altered T-cell subsets (Fiser et al. 1991), and patients with nephrotic syndrome produce cytokines such as lymphotoxin that alter glomerular permeability and eventually give rise to glomerulosclerosis (Koyama et al. 1991). Although there is immunoglobulin deposition within the glomeruli, we have not identified any "self" antigens using sera from affected animals. These antibodies may recognize some rare self component that we have not identified. As fyn-deficient thymocytes may undergo in- 
efficient negative selection to antigens acting late in the maturation cycle, such as endogenous superantigens (Stein et al. 1992), and because c-Yes is expressed in the thymus as well, negative selection may be compromised further in the double mutant and give rise to autoimmune-like responses.

The increased severity of the phenotypes in the double mutants can be interpreted in two ways. First, there is an "additivity" effect, where the combined defects from each mutant are summed together and sufficiently impair the animal to produce the enhanced phenotypes. This scenario is unlikely because the phenotypes associated with the single mutants are relatively mild and restricted. Another interpretation consistent with the double mutant phenotypes is that this group of kinases display a great deal of functional overlap. Therefore, whereas individual Src family kinases function interchangeably in a number of tissues, they may have been conserved in evolution because of selection for divergent functions in individual cell types. The phenotypic consequences of deleting several kinases may result in the removal of redundant biochemical activities in individual or overlapping pathways.

\section{Materials and methods}

\section{Derivation of yes-deficient mice}

Fragments of the c-yes gene were cloned from a NIH-3T3 library using a 1.3-kb partial cDNA probe (a gift of Steve Desiderio). The vectors used to disrupt the locus contained either the PolIIsneobpA expression cassette (Soriano et al. 1991) or $\beta$-geo fusion gene (Friedrich and Soriano 1991). Both were inserted into the XhoI site in exon 7 of the gene. The targeting inserts were released from the plasmid backbone by ApaI digestion and electroporated into AB1 ES cells (McMahon and Bradley 1990) as described previously (Soriano et al. 1991). After 10 days growth in $300 \mu \mathrm{g} / \mathrm{ml}$ of G418 (total powder), either pools of colonies (for Pol2sneobpA) or individual clones ( $\beta$-geo) were picked and analyzed by PCR to identify ES cells that contained the mutant allele. The PCR buffer was described previously (Soriano et al. 1991) and utilized a c-yes specific primer $\left(5^{\prime}\right.$ ACAGTGTTAATGAGGCCATGAACC-3') and neo primer (5'TGGCTACCCGTGATATTGCT- $3^{\prime}$ ). The amplification was maintained for 40 cycles under the following conditions: $30 \mathrm{sec}$ at $93^{\circ} \mathrm{C} ; 30 \mathrm{sec}$ at $55^{\circ} \mathrm{C} ; 3 \mathrm{~min}$ at $65^{\circ} \mathrm{C}$. Candidate clones were confirmed by Southern blot analysis of PstI-digested genomic DNA.

\section{Kinase assays and immunoblot analysis}

Brain extracts were prepared in RIPA buffer, and $250 \mu \mathrm{g}$ of protein was incubated with $1 \mu \mathrm{l}$ of $3 \mathrm{H} 9$ anti-Yes antiserum (Sukegawa et al. 1990). The immune complexes were collected by incubating with formalin-fixed Staphylococcus aureus (Calbiochem), incubated with $5 \mu \mathrm{Ci}\left[\gamma^{-32} \mathrm{P}\right] \mathrm{ATP}$ in $10 \mathrm{mM}$ Tris- $\mathrm{HCl} / \mathrm{pH}$ 7.4), $5 \mathrm{mM} \mathrm{MnCl}_{2}$, and $1 \mathrm{mM} \mathrm{ATP}$ and, finally, analyzed on a $7.5 \%$ SDS-polyacrylamide gel. Brain extracts were also subjected to immunoblot analysis for the presence of Yes protein. Filters were blocked with milk and incubated with mAb $3 \mathrm{H} 9$.

To assess the relative solubility of Src kinases, tissues were homogenized using a polytron in $1 \%$ digitonin buffered with 50 $\mathrm{mm}$ Tris ( $\mathrm{pH} 7.5$ ) and supplemented with $30 \mathrm{~mm}$ sodium pyrophosphate, $20 \mu \mathrm{M} \mathrm{ZnCl}_{2}, 1 \mathrm{~mm}$ vanadate, $100 \mathrm{Kallekrein} \mathrm{inhib-}$ itory units $\langle\mathrm{KIU}\rangle / \mathrm{ml}$ of aprotinin, and $1 \mu \mathrm{M}$ leupeptin. For comparison, tissue was homogenized in $2 \times$ sample buffer $10.1 \mathrm{M}$ Tris at $\mathrm{pH} 6.8 ; 4 \%$ SDS; $20 \%$ glycerol, plus inhibitors listed above) and boiled for $5 \mathrm{~min}$. Protein samples $(100 \mu \mathrm{g})$ were loaded onto $8.5 \%$ polyacrylamide gels and blotted onto nitrocellulose. The c-Src protein was detected using the mAb 327 (Oncogene Sciences), diluted 1:100, and visualized using the ECL detection kit (Amersham). Blots were scanned and the relative levels of c-Src determined. In some cases, protein extracts were serially diluted to determine a linear range for quantitation purposes.

\section{Histological analysis of mutants}

Embryos were stained with X-gal as described (Friedrich and Soriano 1991). Tissues were dissected from animals and fixed in $10 \%$ neutral buffered formalin for processing for paraffin embedding. A general survey was performed on salivary gland, cervical lymph node, lung, kidneys, heart, esophagus, liver, skin, trachea, thyroid, uterus, ovaries, thymus, urinary bladder, eyes, small intestine, large intestine, pancreas, masseter muscle, tongue, and brain. Sections of $3 \mu \mathrm{m}$ were stained with hematoxylin and eosin. Kidney sections were also stained with PAS, Gomori trichrome, and by the Jones technique. Anti-leukocyte common antigen monoclonal antibody (Cappel) was used with the avidin-biotin complex $(\mathrm{ABC})$ technique in selected tissues. For electron microscopy, tissue was fixed in buffered $3 \%$ glutaraldehyde prior to embedding in Epon for ultrathin sectioning. Tissue for immunofluorescence was snap frozen in 2-methylbutane cooled in liquid nitrogen. Cryostat sections $(4 \mu \mathrm{m})$ were stained with fluoresceinated antibodies (Cappel) to IgG, IgA, IgM, and complement C3. Sections of wild-type spleen served as positive controls.

\section{Acknowledgments}

We acknowledge Dr. Edith Hawkins for her generous help in interpreting the renal pathology. We thank Steve Desiderio for a mouse c-yes cDNA probe. Antibodies were kindly provided by Joe Bolen, Joan Brugge, Jon Cooper, Roger Perlmutter, Marius Sudol, and Tadashi Yamamoto. We also thank Jane Gross and Roger Perlmutter for help with calcium analysis and access to laboratory facilities; Jason Poole for help with pedigree analyses; and our colleagues for critical reading of the manuscript. P.L.S. was partially supported by a fellowship from the National Institutes of Health. This work was supported by grants from the National Institute of Child Health and Human Development to P.S.

The publication costs of this article were defrayed in part by payment of page charges. This article must therefore be hereby marked "advertisement" in accordance with 18 USC section 1734 solely to indicate this fact.

\section{References}

Appleby, M.W., J.A. Gross, M.P. Cooke, S.D. Levin, X. Qian, and R.M. Perlmutter. 1992. Defective T cell receptor signaling in mice lacking the thymic isoform of $\mathrm{p} 59^{\text {fyn }}$. Cell 70: 751-763.

Burkhardt, A.L., M. Brunswick, J.B. Bolen and J.J. Mond. 1991. Anti-immunoglobulin stimulation of B lymphocytes activates src-related protein-tyrosine kinases. Proc. Natl. Acad. Sci. 88: 7410-7414.

Clark, E.A. and J.S. Brugge. 1993. Redistribution of activated pp $60^{\text {c-src }}$ to integrin-dependent cytoskeletal complexes in thrombin-stimulated platelets. Mol. Cell. Biol. 13: 18631871. 
Cooke, M.P. and R.M. Perlmutter. 1989. Expression of a novel form of the fyn proto-oncogene in hematopoietic cells. New Biol. 1: 66-74.

Cooke, M.P., K.M. Abraham, K.A. Forbush, and R.M. Perlmutter. 1991. Regulation of $\mathrm{T}$ cell receptor signaling by a src family protein-tyrosine kinase (p59 $\left.{ }^{f y n}\right)$. Cell 65: 281-291.

Cotton, P.C. and J.S. Brugge. 1983. Neural tissues express high levels of the cellular $s r c$ gene product $\mathrm{pp} 60^{\mathrm{c}-s r c}$. Mol. Cell. Biol. 3: 1157-1162.

Courtneidge, S.A., R. Dhand, D. Pilat, G.M. Twamley, M.D. Waterfield, and M.F. Roussel. 1993. Activation of Src family kinases by colony stimulating factor- 1 and their association with its receptor. EMBO I. 12: 943-950.

Fiser, R.T., W.C. Arnold, R.K. Charlton, R.W. Steele, S.H. Childress and B. Shirkey. 1991. T-lymphocyte subsets in nephrotic syndrome. Kidney Int. 40: 913-916.

Friedrich, G. and P. Soriano. 1991. Promoter traps in embryonic stem cells: A genetic screen to identify and mutate developmental genes in mice. Genes \& Dev. 5: 1513-23.

Gertler, F.B., K.K. Hill, M.J. Clark, and F.M. Hoffmann. 1993. Dosage-sensitive modifiers of Drosophila abl tyrosine kinase function: prospero, a regulator of axonal outgrowth, and disabled, a novel tyrosine kinase substrate. Genes \& Dev. 7: 441-453.

Golden, A., S.P. Nemeth, and J.S. Brugge. 1986. Blood platelets express high levels of the pp60 ${ }^{\text {c-src }}$-specific tyrosine kinase activity. Proc. Natl. Acad. Sci. 83: 852-856.

Grant, S.G.N., T.J. O'Dell, K.A. Karl, P.L. Stein, P. Soriano, and E.R. Kandel. 1992. Impaired long-term potentiation, spatial learning, and hippocampal development in fyn mutant mice. Science 258: 1903-1910.

Hamaguchi, M. and H. Hanafusa. 1987. Association of $\mathrm{p} 60^{\text {src }}$ with Triton X-100-resistant cellular structure correlates with morphological transformation. Proc. Natl. Acad. Sci. 84: 2312-2316.

Horne, W.C., L. Neff, D. Chatterjee, A. Lomri, J.B. Levy, and R. Baron. 1992. Osteoclasts express high levels of pp60 $0^{\text {c-src }}$ in association with intracellular membranes. I. Cell Biol. 119: 1003-1013.

Imamoto, A. and P. Soriano. 1993. Disruption of the csk gene, encoding a negative regulator of Src family tyrosine kinases, leads to neural tube defects and embryonic lethality in mice. Cell 73: 1117-1124

Klages, S., D. Adam, K. Class, J. Fargnoli, J.B. Bolen, and R.C. Penhallow. 1994. Ctk: A protein-tyrosine kinase related to Csk that defines an enzyme family. Proc. Nat1. Acad. Sci. 91: 2597-2601.

Klages, S., D. Adam, E. Eiseman, J. Fargnoli, S.M. Dymecki, S.V. Desiderio, and J.B. Bolen. 1993. Molecular cloning and analysis of cDNA encoding the murine c-yes tyrosine protein kinase. Oncogene 8: 713-719.

Koyama, A., M. Fujisaki, M. Kobayashi, M. Igarashi, and M. Narita. 1991. A glomerular permeability factor produced by human T cell hybridomas. Kidney Int. 40: 453-460.

Kypta, R.M., Y. Goldberg, E.T. Ulug, and S.A. Courtneidge. 1990. Association between the PDGF receptor and members of the src family of tyrosine kinases. Cell 62: 481-492.

Louie, R.R., C.S. King, A. MacAuley, J.D. Marth, R.M. Perlmutter, W. Eckhart and J.A. Cooper. 1988. p56 $6^{\text {lck }}$ protein-tyrosine kinase is cytoskeletal and does not bind to polyomavirus middle $\mathrm{T}$ antigen. J. Virol. 62: 4673-4679.

Lowe, C., T. Yoneda, B.F. Boyce, H. Chen, G.R. Mundy and P. Soriano. 1993. Osteopetrosis in Src-deficient mice is due to an autonomous defect of osteoclasts. Proc. Natl. Acad. Sci. 90: 4485-4489.

Lowell, C.A., P. Soriano, and H.E. Varmus. 1994. Functional overlap in the $s r c$ gene family: Inactivation of $h c k$ and $f g r$ impairs natural immunity. Genes \& Dev. 8: 387-398.

McMahon, A.P. and A. Bradley. 1990. The Wnt-1 (int-1) protooncogene is required for development of a large region of the mouse brain. Cell 62: 1073-1085.

Molina, T.J., K. Kishihara, D.P. Siderovski, W. van Ewijk, A. Narendran, E. Timms, A. Wakeham, C.J. Paige, K.U. Hartmann, A. Veillette, D. Davidson, and T.W. Mak. 1992. Profound block in thymocyte development in mice lacking p56 $6^{\text {lck }}$. Nature 357: 161-164.

Nada, S., T. Yagi, H. Takeda, T. Tokunaga, H. Nakagawa, Y. Ikawa, M. Okada, and S. Aizawa. 1993. Constitutive activation of Src family kinases in mouse embryos that lack Csk. Cell 73: 1125-1135.

Okada, M., S. Nada, Y. Yamanishi, T. Yamamoto, and H. Nakagawa. 1991. CSK: A protein-tyrosine kinase involved in regulation of src family kinases. J. Biol. Chem. 266: 2424924252.

Ralston, R. and J.M. Bishop. 1985. The product of the protooncogene c-src is modified during the cellular response to platelet derived growth factor. Proc. Natl. Acad. Sci. 82: 78457849 .

Rudnicki, M.A., P.N. Schnegelsberg, R.H. Stead, T. Braun, H.H. Arnold, and R. Jaenisch. 1993. MyoD or Myf-5 is required for the formation of skeletal muscle. Cell 75: 1351-1359.

Soriano, P., C. Montogomery, R. Geske, and A. Bradley. 1991. Targeted disruption of the c-src proto-oncogene leads to osteopetrosis in mice. Cell 64: 693-702.

Stehelin, D., H.E. Varmus, J.M. Bishop, and P. Vogt. 1976. DNA related to the transforming gene of avian sarcoma virus is present in normal avian DNA. Nature 260: 170-173.

Stein, P., H.-M. Lee, S. Rich, and P. Soriano. 1992. pp59 $9^{\text {fyn }}$ mutant mice display differential signaling in thymocytes and peripheral T cells. Cell 70: 741-750.

Sukegawa, I., T. Akatsuka, I. Sugawara, S. Mori, T. Yamamoto, and K. Toyoshima. 1990. Monoclonal antibodies to the amino-terminal sequence of the c-yes gene product as specific probes of its expression. Oncogene 5: 611-614.

Tsygankov, A.Y., B.M. Broker, J. Fargnoli, J.A. Ledbetter, and J.B. Bolen. 1992. Activation of tyrosine kinase $\mathrm{p} 60^{\mathrm{fyn}}$ following $\mathrm{T}$ cell antigen receptor cross-linking. I. Biol. Chem. 267: 18259-18262.

Twamley, G.M., R.M. Kypta, B. Hall, and S.A. Courtneidge. 1992. Association of Fyn with the activated platelet-derived growth factor receptor: Requirements for binding and phosphorylation. Oncogene 7: 1893-1901.

Twamley-Stein, G.M., R. Pepperkok, W. Ansorge, and S.A. Courtneidge. 1993. The Src family tyrosine kinases are required for platelet-derived growth factor-mediated signal transduction in NIH 3T3 cells. Proc. Natl. Acad. Sci. 90: 7696-7700.

Umemori, H., S. Sato, T. Yagi, S. Aizawa, and T. Yamamoto. 1994. Initial events of myelination involve Fyn tyrosine kinase signalling. Nature 367: 572-576.

Walker, F., J. deBlaquiere, and A.W. Burgess. 1993. Translocation of pp $60^{\mathrm{c}-s r c}$ from the plasma membrane to the cytosol after stimulation by platelet-derived growth factor. $/$. Biol. Chem. 268: 19552-19558.

Zhao, Y.-H., J.G. Krueger, and M. Sudol. 1990. Expression of cellular-yes protein in mammalian tissues. Oncogene 5: 1629-1635. 


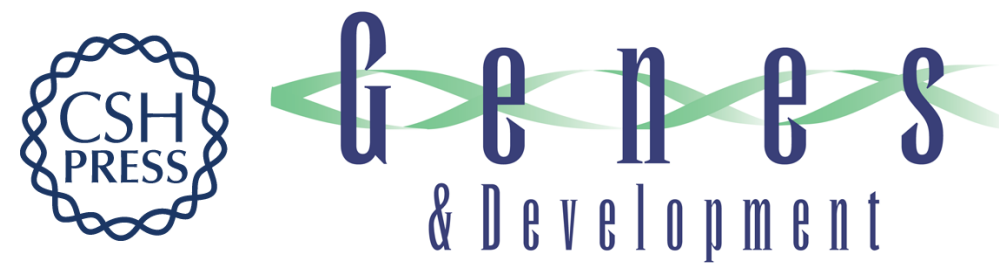

\section{Combined deficiencies of Src, Fyn, and Yes tyrosine kinases in mutant mice.}

$\mathrm{P} L$ Stein, $\mathrm{H}$ Vogel and $\mathrm{P}$ Soriano

Genes Dev. 1994, 8:

Access the most recent version at doi:10.1101/gad.8.17.1999

References This article cites 38 articles, 18 of which can be accessed free at:

http://genesdev.cshlp.org/content/8/17/1999.full.html\#ref-list-1

License

Email Alerting

Service

Receive free email alerts when new articles cite this article - sign up in the box at the top right corner of the article or click here.

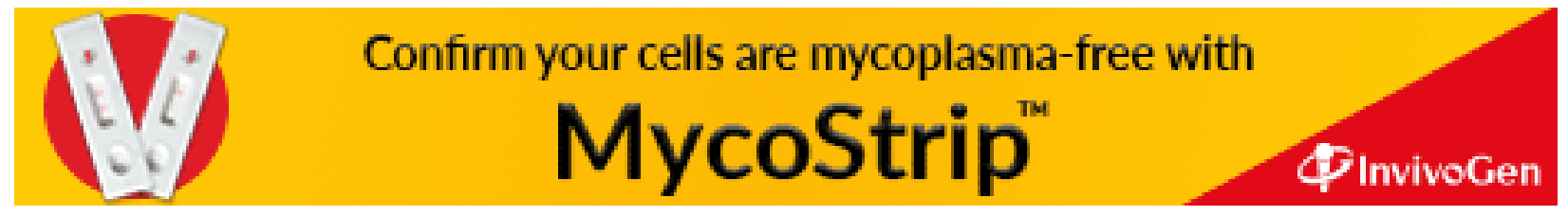

